\title{
Teoria psicanalítica, sexo e gênero: articulações em uma perspectiva anti-essencialista
}

\section{Psychoanalytical theory, sex and gender: dialogue in an anti-essentialist perspective}

\author{
João Eduardo Torrecillas Sartori', Alexandre Mantovani²
}

\begin{abstract}
Resumo
O presente artigo discute contribuições psicanalíticas aos estudos sobre sexualidade e gênero. A teoria psicanalítica freudiana recebeu diversas críticas por parte dos teóricos de estudos de gênero que reconheceram, nas hipóteses aventadas por Freud, atitudes reducionistas e deterministas. Todavia, Freud foi um dos primeiros autores a propor leituras sobre a sexualidade que, justamente, evitavam tanto o reducionismo no entendimento de certas práticas sexuais - deixando de considerá-las sob uma perspectiva psicopatológica -, quanto a consideração segundo a qual haveria uma pré-determinação na sexualidade e nos gêneros, em termos biológicos. Com base no estudo histórico-epistemológico sobre o tema da sexualidade na psicanálise e na análise de um caso clínico freudiano, propõe-se uma leitura antiessencialista que evita reducionismos no entendimento de questões referentes à subjetivação e privilegia o entendimento da subjetividade inscrita no domínio sociocultural..
\end{abstract}

Palavras-chaves: Psicanálise. Gênero. Cultura. Sexualidade..

\begin{abstract}
This article discusses psychoanalytical contributions to studies on sexuality and gender. Freud's psychoanalytic theory was criticized by many scholars of gender studies that have recognized, in the Freudian hypotheses, reductionist and determinist attitudes. However, Freud was one of the first authors to propose readings on sexuality precisely avoiding both the reductionism in the understanding of certain sexual practices - failing to consider them under a psychopathological perspective - and the consideration that there would be a predetermination in sexuality and gender, in biological terms. Based on historical and epistemological study on the topic of sexuality in psychoanalysis, and by the analysis of a Freudian clinical case, we propose an anti-essentialist reading that avoids reducing issues of subjectivity and focus on the understanding of subjectivity inscribed in the sociocultural domain.
\end{abstract}

Keywords: Psychoanalysis. Gender. Culture. Sexuality.

1 Graduando em medicina. Coordenador do GETP-FAMERP e Acadêmico de Medicina da FAMERP. E-mail: joao.sartori@hotmail.com.br

2 Doutor em Psicologia pela FFCLRP-USP. Professor do Departamento de Enfermagem Psiquiátrica e Ciências Humanas da EERP-USP. 


\section{Introdução}

Enquanto prática clínica, a psicanálise propõe-se a uma emancipação do sujeito por uma expansão de seu conhecimento acerca do próprio inconsciente. Porém, a escuta propiciada na clínica psicanalítica permite que se aborde o sujeito sem a necessidade de se estancarem, nele, quaisquer essências - quer sejam masculina/feminina, heterossexual/homossexual, sádico/masoquista, etc. -, apenas se destacando, justamente, seus direcionamentos pulsionais. Assim, permite-se que o analista se abstenha da formulação de enunciados que resultariam em categorizações identificatórias, potencialmente redutoras e estanques (SARTORI; MANTOVANI, 2016).

Com o estabelecimento, proposto já na teorização freudiana acerca da sexualidade, da noção de perversopolimorfismo infantil, apresentar-se-ia, no que se refere ao sujeito, uma relação de não-necessidade apriorística entre a pulsão e o seu objeto - por meio do qual aquela viria a se realizar -, fazendo com que este passasse a ser concebido como variável e não mais como pré-determinado. Desse modo, a teoria psicanalítica permitiria que se entendesse a eleição objetal como o resultado de um percurso subjetivo singular - além de inconsciente - que se constituiria de modo a ser condicionado e influenciado pelo sistema sociocultural, mas não determinado por este (SARTORI; MANTOVANI, 2016).

De modo análogo, proceder-se-ia com o estabelecimento da noção de caracteres sexuais mentais, que possibilitaria pensar o conceito de gênero, em suas possíveis categorias, como não sendo natural e prédeterminado, mas como uma categoria identificatória somente existente em sociedades sexuadas e generizadas e cuja assunção subjetiva adviria de complexos processos identificatórios, também condicionados e influenciados pelo sistema sociocultural, mas não determinados por este (SARTORI; MANTOVANI, 2016).

Somente com Stoller (1966), o termo "gênero" passou a constituir formalmente o domínio conceitual da psicanálise. No entanto, tal introdução não teria ocorrido de maneira consensual, ainda hoje havendo discordâncias quanto à sua aceitação no campo psicanalítico. Assim, se, por um lado, como aponta Ceccarelli (2010), na própria teoria freudiana existiria a abertura para se pensarem questões de gênero - fazendo-se o uso da noção de "caracteres sexuais mentais" -, por outro, certos autores, tais como Lacan, rejeitariam a articulação metapsicológica daquele conceito.

Em uma perspectiva histórica, teóricos como Lattanzio (2011) teriam se proposto a situar a noção de gênero na psicanálise, realizando um percurso teórico que discutiria as limitações e as implicações de sua articulação metapsicológica nas teorias psicanalíticas de diversos autores, perpassando Freud, Lacan e Laplanche. Também, o autor, em uma perspectiva que se poderia denominar anti-essencialista, teria se proposto não somente a criticar tais teorias psicanalíticas em relação à essencialização a que recorreram algumas de suas hipóteses e conceitos, mas a teorizar de modo inovador, refundando a psicanálise frente a uma possibilidade de desessencialização destes últimos, desconstruindo-se certos conceitos - incluindo-se, nisto, o próprio conceito de gênero -, situando-os histórica e socialmente.

Nesse contexto, levando em consideração a perspectiva mencionada - segundo a qual se situam, histórica e socialmente, seus conceitos -, o presente estudo se propõe à discussão histórico-epistemológica acerca da temática referente à sexualidade e ao gênero na psicanálise, articulando seus conceitos metapsicologicamente. Por fim, recorre à análise de um caso clínico freudiano, propondo-se a uma leitura que evitaria, justamente, uma naturalização e uma redução de certas categorias e noções, privilegiando, em seu lugar, o entendimento de uma subjetividade inscrita no domínio sociocultural.

\section{Identificação, Identidade, Cultura e Sexuação}

As diversas formas de articulação entre teoria psicanalítica e ciências sociais, possuem, nos conceitos de identidade e de identificação, importantes instrumentos articuladores. O conceito de identidade, por motivos incertos, não integra formalmente o domínio conceitual psicanalítico, sendo, entretanto, habitual que seja aludido indiretamente em psicanálise (CECCARELLI, 1997). Já 
a noção de identificação revela-se fundamental na teoria psicanalítica, fazendo-se um de seus conceitos centrais, apesar de não ser formalmente integrada ao domínio conceitual das ciências sociais.

Entende-se identificação como o processo psíquico inconsciente por meio do qual um indivíduo assimila um aspecto de um terceiro - como uma noção ou um traço de caráter, por exemplo -, tornando-se, em tal aspecto, semelhante a este último. É, sobretudo por meio do processo identificatório, que o psiquismo se constitui, internalizando-se, em última análise, os elementos simbólicos do sistema sociocultural em que o sujeito se insere no decorrer de sua história singular. Por isso, faz-se imprescindível que se recorra ao conceito de identificação ${ }^{3}$ na compreensão da subjetivação.

Identidade, por sua vez, pode ser entendida como o resultado, conscientemente percebido, do processo inconsciente de síntese - pontual - entre as muitas representações de si - que, em razão da possibilidade de serem incompatíveis entre si, podem fazer surgir um conflito. Ainda, poderia ser entendida como o resultado ${ }^{4}$ , conscientemente percebido, da síntese entre os muitos processos identificatórios, o que o sujeito se colocaria a realizar em sua tentativa de definir a si próprio, conferindo, àquela, certa unicidade (CECCARELLI, 1997).

Nesse contexto, pode-se pensar que, justamente por sua necessidade de conferir unicidade ao sujeito, a identidade poderia depender de uma resolução de conflito: para que se proceda com a mencionada síntese que a possibilita, um provável conflito, existente entre certos elementos, irredutíveis uns sobre os outros, deverá ser momentaneamente solucionado. Certas representações devem ser abandonadas ou modificadas para que possam dar sentido a um todo coeso.

Desse modo, trata-se, antes, de um movimento, dado que, em decorrência da continuidade dos processos identificatórios ao longo da história individual, uma identidade constituída em um dado momento provavelmente não será idêntica àquela constituída no momento imediatamente posterior. Contudo, é justamente atribuída à identidade, enquanto resultado de um processo de síntese, a sensação de continuidade do ser, que não concebe ser algo que não ele próprio e o mesmo de sempre - em que se apresenta um aparente paradoxo, se considerada a mencionada transformação pela qual passa a identidade.

Por outro lado, é também a identidade, enquanto resultado deste processo de síntese das representações de si - com o propósito de definir a si próprio - que permite, ao indivíduo, expressar aquilo à que se assemelha e aquilo de que se distingue. Nesse sentido, o conceito de identidade é empregado, tanto em ciências sociais como em teorias psicológicas, de modo mais específico, denotando a noção - e o consequente sentimento de pertencimento a um grupo simbólico - a que se denominará categoria identificatória. E, assim, pode-se falar, para se citarem alguns exemplos, em identidade nacional, identidade étnico-racial, identidade sexual e identidade de gênero.

Identidade sexual, nesta perspectiva, consistirá na referência que o sujeito possui acerca de sua própria constituição sexual, podendo ser entendida como a noção segundo a qual se pertenceria a um sexo específico, resultando do fenômeno de identificação sexual - também referido, de modo mais restrito, como assunção de um sexo -, constituída ao longo do desenvolvimento em um complexo processo cognitivo que terminará por inserir o indivíduo em seu sistema sociocultural e, portanto, desde já, somente ocorrendo em sociedades sexuadas. De modo análogo, identidade de gênero seria a referência que o sujeito possuiria acerca de seu próprio gênero, podendo ser entendida como a noção segundo a qual se pertenceria a um gênero específico, resultando do fenômeno de identificação de gênero - também referido como assunção de um gênero - constituída de modo semelhante à identidade sexual e, portanto, desde já, somente ocorrendo em sociedades generizadas. E, ainda nesta perspectiva, poder-se-ia falar em identidade de orientação sexual, que culminaria na identificação do sujeito com uma

\footnotetext{
${ }^{3}$ Segundo Stenner (2004), o conceito de identificação teria sido formulado por Freud e consolidado por Lacan.

${ }^{4}$ Nesse sentido, a identidade se possibilitaria a partir de uma miscelânea de identificações com os objetos ao qual o sujeito tenha sido apresentado.
} 
das categorias identificatórias de orientação sexual, culturalmente previstas, tacitamente ou não.

Como se verifica, cada sistema sociocultural apresenta sua própria moral, conjunto de normas dadas como válidas e que predizem, aos seus integrantes, o modo como deverão se comportar em sociedade. Contudo, é perceptível - e problemático - que as normas morais apresentam condicionais de categorias identificatórias ${ }^{5}-$ sexo, gênero, orientação sexual, raça/etnia, nacionalidade, entre outras -, de modo que, com isso, o papel social a ser desempenhado pelo indivíduo esteja ancorado àquelas, por mais que tal fato possa ser, inclusive culturalmente, velado - e negado com veemência por seus integrantes e que se demonstre complexo.

Assim, valerá ressaltar que as categorias identificatórias terminam por condicionar os sujeitos diferentemente, de modo que, ao pertencer a alguma determinada categoria, um indivíduo será compelido a se submeter a uma moral específica para o grupo ao qual pertence, o que consistirá, geralmente, em instrumento de reforço de opressão, legitimando-se preconceitos e atitudes discriminatórias, bem como desigualdade socioeconômica e política entre os grupos previstos culturalmente.

Ainda, tem se mostrado um fato comum às tantas sociedades de que se tem registro, da antiguidade à contemporaneidade, independentemente de suas formas de organização, a existência da categoria de sexo [biológico], geralmente dicotomizada entre homem e mulher, fenômeno que, genericamente, se denominaria sexuação sociocultural. Em muitos casos, a princípio, o primeiro sendo entendido como possuidor de pênis, e a segunda sendo entendida como possuidora de vagina.

Por outro lado, uma crítica de perspectiva antiessencialista - que incluiria, por exemplo, a perspectiva de Foucault e os estudos Queer - demonstraria que as categorizações de uso comum nos sistemas socioculturais, quaisquer que sejam - sexo, gênero, orientação sexual, raça, etnia, entre outros -, não são naturais e essenciais, mas históricas - construtos conceituais. No entanto, isso não significará a negação de possibilidade de existência à diferença anatômica, mas apenas a evidenciação de que a criação dos conceitos de homem e mulher a partir da presença de órgãos genitais masculinos e femininos, respectivamente, consiste em uma convenção arbitrária, que se fez surgir provavelmente em um passado remoto - talvez em função da importância que se atribuía à reprodução, naquele momento histórico, na organização social - e que persistiu como um elemento sociocultural, tendo sido reforçada a sua naturalização no decorrer da história da humanidade com propósitos socialmente situáveis, apesar de não se evidenciar tal fato.

Nesse sentido, não se deverá considerar, como sendo necessários, os usos ideológicos específicos que fazem, as variadas sociedades, da diferença anatômica. Trata-se de uma falácia, a noção de que seria natural - e, a priori, necessária - não somente a correspondência entre a posse de determinados dados anatômicos, o pertencimento a um determinado sexo biológico, o pertencimento a um determinado gênero ${ }^{6}$ , e o direcionamento do desejo sexual a determinada categoria de objetos, mas a própria existência de tais categorias. Em tese, poderia existir uma sociedade não sexuada e não generizada, ou seja, que não concebesse ou que não atribuísse maior importância à diferença anatômica, não criando recortes teóricos específicos da realidade - conceitos e teorias - para significá-la de modo a se cindir a realidade social a partir daquela.

Assim, a ideia de que haveria uma necessária continuidade entre a presença de um pênis, o pertencimento à categoria masculina, a assunção de uma masculinidade e a atração sexual por mulheres, ou entre a presença de uma vagina, o pertencimento à categoria feminina, a assunção de uma feminilidade e a atração sexual por homens, foi naturalizada naquilo que Butler (1990) chamaria heterossexualidade normativa ${ }^{7}$, tanto quanto a própria existência desses conceitos.

\footnotetext{
5 A presença de categorizações é minimamente necessária, dado que possibilita a subjetivação em função de processos identificatórios Nesse contexto, Ceccarelli (1997) diria que, "por falta de identidade, o ser humano é "condenado" à identificação".

${ }^{6}$ Incluindo-se a identidade de gênero e o papel de gênero.

7 Esta estando relacionada com a denominada "matriz heterossexual".
} 
Nesse contexto, a autora (BUTLER, 1990) afirmaria que a identidade de gênero seria uma construção ilusória, sendo as próprias “expressões de gênero” as responsáveis pela reiteração desta "identidade de gênero" construída e pela manutenção da ordem social mencionada ${ }^{8}$. Não haveria uma essência - apriorística - concernente à categoria de gênero, o que implicaria a necessidade de uma constante repetição de estereotipias arbitrariamente convencionadas para que se mantivesse a ilusão de que aquela existe. Assim, entende-se a "identidade de gênero" como um fenômeno constituído performativamente ${ }^{9}$, pelas próprias "expressões de gênero" consideradas, paradoxalmente, como o seu resultado.

\section{Sobre a Subjetivação em Sociedades Sexuadas e Generizadas}

Apesar de os conceitos de sexo e gênero serem, conforme aponta Butler (1990), construções sociais, histórica e socialmente situáveis e, na perspectiva assumida, problemáticas, estes têm se mostrado não somente presentes, mas dados elementares na constituição de identidades - e, consequentemente, na subjetivação -, nos mais diferentes sistemas socioculturais contemporâneos, constituindo o psiquismo e determinando papéis sociais e relações de poder. Em sociedades sexuadas e generizadas, a subjetivação pressupõe, dentre inúmeros e complicados processos identificatórios, a assunção de um sexo ${ }^{10}$ e a assunção de um gênero ${ }^{11}$.

Desde que Stoller (1966) articulou o conceito de gênero na teoria psicanalítica, utilizou-o como se referindo a uma instância psicossocial, em oposição ao conceito de sexo, que, em sua perspectiva teórica, seria referente à instância biológica. Com isso, teria reforçado implicitamente o problemático binarismo "natureza/ cultura", dando ao sexo a conotação de biológico - e natural -, mascarando o fato de que este conceito, tal como o conceito de gênero, seria uma construção social (CECCARELLI, 2010).

Autores como Laplanche (2003), no entanto, mantendo a articulação metapsicológica do conceito de gênero, procuraram demonstrar como se constituiriam a identidade sexual e a identidade de gênero nas sociedades em questão, além de evidenciar o fato de que, psiquicamente [nas sociedades sexuadas e generizadas], a segunda primaria sobre a primeira, sendo, os caracteres anatômicos sexuais, uma forma de se estancar psiquicamente a identidade de gênero. Seguirá, então, uma perspectiva sintética acerca do processo de subjetivação frente à sexuação e à generização nas sociedades industriais contemporâneas.

Tradicionalmente, nestas sociedades, com o nascimento da criança - e, na atualidade, anteriormente a este, com o advento tecnológico da ultrassonagrafia -, inicia-se a consolidação da crença, por parte de seus responsáveis, segundo a qual aquela pertenceria a um determinado sexo, o que se fundamenta em uma leitura de seus dados anatômicos - mais especificamente, aqueles que seriam entendidos como as suas genitálias. $\mathrm{E}$ tal crença, inicialmente externa à criança, no decorrer do tempo recebe reforços que a tornam socialmente incontestável, por meio de fatos tais como o reconhecimento comum de seu sexo e a sua inscrição no cartório civil (CECCARELLI, 2010).

Desde aquele momento, a crença consolidada levaria à designação do gênero do recém-nascido em suposta correspondência $^{12}$ com o sexo lido e faria com que aquele fosse tratado de acordo com os atributos socialmente instituídos para o gênero que lhe foi designado. E será por meio da internalização de uma infinidade de elementos simbólicos, que se estende do discurso dos pais - sobre e para com a criança-aos presentes que lhe serão dados desde

\footnotetext{
8 As expressões (performances) de gênero somente são significadas no interior de uma estrutura constituída discursivamente: a heterossexualidade compulsória.

9 O conceito de "performatividade" de Judith Butler (1990) indicaria a qualidade daquilo que se constitui na sua própria performance. Assim, o gênero, enquanto fenômeno performático, não seria natural - no sentido de pertencer à ordem do essencial.

${ }^{10}$ Sentimento segundo o qual se pertenceria a um sexo específico; assunção de um sexo.

${ }^{11}$ Sentimento segundo o qual se pertenceria a um gênero específico; assunção de um gênero.

${ }^{12}$ Isto porque, nestas sociedades, entende-se, como norma, uma linearidade entre certos elementos anatômicos (pênis/vagina), certos sexos (macho/fêmea), certos papéis de gênero (masculino/feminino) e certas identidades de gênero (homem/mulher).
} 
o seu nascimento, que ela passará a conceber a si própria como um menino ou uma menina, além de começar a fazer uma ideia do que venham a representar estes conceitos em sua realidade social (CECCARELLI, 2010).

A criança inicia o desenvolvimento da personalidade possuindo, como primeiros objetos de identificação, os seus responsáveis. No ocidente em geral, apesar das recentes transformações ocorridas nas configurações familiares, muito comumente os responsáveis são os pais, havendo um núcleo familiar referido como tradicional. Por intermédio de sua relação com aqueles - e, posteriormente, com outras figuras de autoridade, em ambiente familiar, escolar, ou outros -, a criança introjetará os elementos simbólicos acerca da cultura própria à sociedade em que se insere. Assim, enquanto menino ou menina, passará, gradativamente, a compreender as suas condições de existência social enquanto ser sexuado e generizado ou seja, os papéis de gênero de sua própria sociedade. Em muitos casos, a criança terá o seu psiquismo ideais, valores, afetividade - e o seu comportamento significativamente condicionados de acordo com as convenções sociais - aquilo que é proscrito/prescrito para o gênero ${ }^{13}$ que lhe fora designado.

Ao longo de seu desenvolvimento, gradativamente, a criança passará a compreender o registro dentro do qual deverá se comportar em razão do gênero ao qual fora designada, podendo, este último, estar em acordo/ desacordo com o sexo e/ou o gênero com que ela se identifica - e a que ela sente pertencer. E, durante todo o seu desenvolvimento, a crença de que pertenceria a um sexo/gênero específico poderá ser tanto reafirmada como contestada por diversos elementos simbólicos, que irão da opinião comum acerca de seu sexo/gênero à sua própria psicossexualidade - e, até mesmo, à leitura que faz de seu próprio corpo sexuado conforme a cultura em que se desenvolve (CECCARELLI, 2010).

Nesse sentido, a heterogeneidade das mensagens - elementos simbólicos - com as quais a criança se depara, faz com que existam ruídos ${ }^{14}$ no processo de sua designação em uma categoria identificatória específica. E uma atitude isolada - como, para a exemplificação do dito, a denominação de um menino com um nome considerado socioculturalmente como masculino -, não será suficiente para manter o processo de designação em um sentido único. Para tanto, em lugar disso, farse-á necessário um conjunto complexo de eventos, significados de modo específico no sistema sociocultural em que se insere a criança (LATTANZIO, 2011).

A criança recebe e assume as mensagens de designação de um gênero específico, mas também, simultaneamente, percebe os ruídos que tornam esse processo mais complexo, gerando, no processo de assunção de um gênero, uma aparente descontinuidade que impõe, àquela, um trabalho de simbolização do ruído (excesso) que lhe chega. Em uma ordem social cis-heteronormativa, tal simbolização do excesso, uma espécie de tradução organizadora, poderia ser facilitada pelo sexo [biológico], que viria a fixar o gênero, dandolhe aparente estabilidade (LATTANZIO, 2011).

Nesse contexto, poder-se-ia dizer que, na constituição do psiquismo nas sociedades em questão, o gênero prima sobre o sexo. Antes mesmo que a criança se identifique com um sexo especifico, compreendendo-se, geralmente, como pertencente ao sexo masculino ou ao sexo feminino, a identidade de gênero seria internalizada como consequência do processo de identificação passiva ${ }^{15}$ , formulado por Ribeiro (2010) para fazer referência ao modelo primário de identificação, remetendo à completa passividade da criança frente à psicossexualidade do adulto nos primeiros momentos de sua existência. Desse modo, em relação à identificação passiva, seria mais adequado dizer que "a criança não se identifica", mas, antes, "a criança é identificada".

Assim, em sociedades sexuadas e generizadas, no processo de subjetivação, o gênero antecederia o sexo e seria anterior à própria tomada de consciência. E,

${ }^{13}$ Neste caso, cita-se o gênero em decorrência da importância assumida por esta categoria identificatória na análise realizada, mas é certo que serão também importantes as demais categorias identificatórias assumidas pelo indivíduo.

${ }^{14}$ Excessos, mensagens que indicariam, à criança, que ela seria/possuiria algo contrário ao que se espera para o gênero a que fora designada.

${ }^{15}$ Retomado por Laplanche (2003) ao chamá-lo de "identificação por", fazendo um contraponto à "identificação a". 
como se verifica, em tais sociedades, a assunção do sexo se faz não somente secundária, mas organizadora, sendo também uma forma de simbolização dos excessos concernentes à assunção do gênero e vindo a atender às exigências narcísicas de estabilização de uma inevitável multiplicidade (LATTANZIO, 2011).

Ressalta-se que, se a criança for criada com convicção no gênero que lhe foi atribuído, tendo se realizado sua identificação passiva - portanto, tendo sido também simbolizados os ruídos que lhe advieram na designação de seu gênero -, sua identidade de gênero se mostrará relativamente estável, o que independerá de seu sexo [biológico] - podendo, mesmo, sua identidade de gênero se contrapor ao esquema cis-heteronormativo vigente. Nestes casos, será o gênero de atribuição, e não o sexo [anatomobiológico], que assegurará à criança o sentimento de ser menino ou menina. Nesse contexto, ainda que a criança apresente genitálias não correspondentes, em tal esquema, ao seu gênero de atribuição, provavelmente se colocará de acordo com este último, o que não significa que não possa apresentar, em algum momento, conflitos psíquicos relativos à sua própria ruptura com a linearidade entre sexo e gênero preconizada pela cis-heteronormatividade que fundamenta sua realidade social.

Por outro lado, também haverá a possibilidade de o gênero conscientemente atribuído à criança pelos pais não ser assumido pela criança - ou de, após ter sido aparentemente assumido, passar a ser renegado -, o que poderá ocorrer por uma infinidade de motivos, sobretudo de ordem psicodinâmica e inconsciente. E caso o gênero atribuído à criança, mas não assumido por esta, seja aquele que, em tal esquema, corresponderia ao seu sexo [biológico], poderá ocorrer uma estabilização de sua identidade de gênero de modo que, no esquema cisheteronormativo, esta seria contrária à preconizada, o que fará com que a criança acredite não ter suas genitálias e, posteriormente, seu sexo -, de acordo com seu gênero, podendo decorrer, disso, conflitos psíquicos - como aquele em que sentiria que o próprio corpo não lhe pertence.
Conforme Ceccarelli (2010), faz-se perceptível que a criança, estando imersa, desde o seu nascimento, no sistema simbólico sexuado - e generizado - da sociedade na qual se insere, internalizará e passará a conceber, irrefletidamente, a existência de seu pai e de sua mãe, posicionando-se de acordo com aquele a que acredita se assemelhar e se entendendo como diferente do outro. Gradativamente, em um complexo processo de subjetivação, que contará com identificações passivas e ativas - e com a simbolização dos excessos que lhe possam advir -, transformará o seu corpo anatômico, supostamente circunscrito no plano do real, em um corpo sexuado e generizado, circunscrito no plano do simbólico (CECCARELLI, 2010).

Mas, vale ressaltar que, como em qualquer identidade que o sujeito evoque, nas identidades sexual e de gênero, os recalcamentos presentes desde o início de sua vida impedem o acesso aos cenários fantasmáticos que formam o alicerce daquilo que ele comunicará com tal identidade. Nesta perspectiva, tratar da questão identitária envolverá, inevitavelmente, a referência a conceitos psicanalíticos como o de inconsciente, em articulação com outros aspectos do psiquismo e, indiretamente, da realidade social na qual o indivíduo se insere. Por fim, poder-se-ia dizer que a etnopsicanálise, enquanto articula também as perspectivas antropológica e psicanalítica, colocar-seia como campo fundamental no estudo interdisciplinar da subjetivação, da sexualidade e de gênero.

\section{Contextualização: um Caso Clínico Freudiano}

Com o propósito de que se contextualize a exposição anterior, seguirá a discussão de um estudo de caso de Freud (1976a) intitulado "Psicogênese de um caso de homossexualismo em uma mulher"16. Esse artigo trata de um dos estudos pioneiros acerca da homossexualidade feminina e exemplifica o modo como a psicanálise, desde o seu surgimento, não recorre, tanto em relação à terapêutica, quanto em

\footnotetext{
16 O termo "homossexualismo" foi utilizado na edição selecionada da mencionada obra de Freud. No entanto, atualmente, o termo mais adequadamente empregado, neste caso, seria "homossexualidade".
} 
relação à teoria referente à formação da personalidade, a uma perspectiva determinista e reducionista.

Nesse estudo, Freud apresenta comentários acerca do atendimento de uma jovem vienense que havia tentado suicídio em um episódio que envolvera questões relativas à sua conduta sexual. Seus pais buscaram o tratamento após o incidente. Freud discute as motivações inconscientes para seu ato relacionando noções a respeito de suas escolhas amorosas (sexuais) e conflitos relativos às mesmas. Enfatiza, nesse sentido, a questão referente às identificações da jovem com suas figuras parentais (imagos) e os aspectos gerais acerca do tratamento e da formação da identidade homossexual em homens e mulheres.

Sobreaapresentaçãodocasoclínico, resumidamente: trata-se de um atendimento solicitado pelos pais da jovem Sidonie Csillag (RIEDER; VOIGT, 2008), que seria publicamente reconhecida, posteriormente, como uma das integrantes do movimento feminista europeu do século XX. De acordo com a descrição de Freud (1976a) e de Rieder e Voigt (2008), Sidonie era uma jovem cujo comportamento em relação às orientações amorosas não se enquadrava nos padrões socialmente esperados na época. Ela mantinha relacionamentos, superficiais, com mulheres. Era de uma família judia em ascensão social e, para a sociedade vienense, a homossexualidade não se fazia aceitável. Um desses relacionamentos envolveu a Baronesa Puttmaker, mulher próxima aos trinta anos que mantinha um estilo de vida que destoava demasiadamente daquele que era socialmente preconizado: morava sozinha e recebia jovens como Csillag em sua casa. A amizade com a baronesa era sofrível para os pais de Sidonie e, em decorrência disto, precipitou-se o ato suicida: em certa ocasião, estando a caminhar ao lado da Baronesa, Sidonie cruzou com seu pai que, ao vê-la em sua companhia, lançou-lhe um olhar de reprovação. Diante de tal atitude, Sidonie jogou-se de uma ponte, ferindose gravemente, mas não se advindo, disso, sequelas graves. A partir de então, os pais da jovem procuraram Freud, um médico judeu, na época já de notável reputação, para possivelmente auxiliar na mudança de comportamento de sua filha.
No entanto, valerá ressaltar, anteriormente à discussão acerca da questão específica referente às suas eleições objetais e à sua identidade, dois aspectos de fundamental relevância acerca da psicanálise enquanto prática terapêutica. Em primeiro lugar, o tratamento psicanalítico depende da vontade própria da pessoa - ou seja, faz-se relacionado com a percepção subjetiva do mal-estar e com o desejo de mudança. Essa colocação assume importância por demarcar o território da psicanálise enquanto prática terapêutica que não supõe uma "cura” universal - no sentido de que seria apriorística - nem um modelo genérico de paciente. Freud, logo na introdução do texto, faz um comentário para a explicação de casos como esse, em que o tratamento de um sujeito é solicitado por terceiros: "Sabe-se bem que a situação ideal para a análise é a circunstância de alguém que, sob outros aspectos, é seu próprio senhor, e está no momento sofrendo de um conflito interno que é incapaz de resolver sozinho; assim leva seu problema ao analista e lhe pede auxílio" (FREUD, 1976a, p. 188). O sofrimento não é uma estrutura objetiva sobre a qual o terapeuta se debruçaria com a finalidade de promover uma mudança. A “cura" psicanalítica depende desse engajamento do paciente e, logo, depende do reconhecimento de si mesmo como enfermo.

Em segundo lugar, a psicanálise, tanto teórica como praticamente, não considera a homossexualidade como doença. No caso de Sidonie Csillag, seu encontro com Freud - promovido pelos pais da jovem -, teve, como motivador, a não aceitação de sua orientação sexual por estes últimos. Assim, o reconhecimento de seus impulsos e de seus comportamentos homossexuais como sintomas, entidades a serem tratadas, não se dava por Sidonie, nem por Freud, mas pelos pais daquela. Em Viena do início do século XX, a homossexualidade não se fazia aceita e, para muitos, era considerada como um comportamento desviante e patológico - como resultante de degeneração. Apesar disso, Freud (1976a) não considera a homossexualidade - referida como "inversão sexual" - como uma patologia: "Se chega a ser tratado, isso se dá principalmente pela pressão de motivos externos, tais como as desvantagens sociais e os perigos ligados a 
sua escolha de objetos; e esses componentes do instinto de auto-conservação mostram-se fracos demais na luta contra os impulsos sexuais" (FREUD, 1976a, p. 189) ${ }^{17}$.

Por meio do excerto supramencionado, Freud considera que a homossexualidade não se configura como um distúrbio, que prejudicaria o funcionamento orgânico e cuja ausência de tratamento acarretaria consequências deletérias. Afirma que a proposição de um suposto "tratamento" da homossexualidade somente se justificaria por pressões sociais - que acarretariam a problemática necessidade da adequação individual aos padrões de conduta socialmente preconizados. Em adição ao exposto, pode-se dizer que a citação anterior exemplifica o fato de Freud não somente desconsiderar a homossexualidade enquanto psicopatologia, mas de demonstrar como o contexto sociocultural influencia na forma como se lida com o comportamento referido como "inversão sexual".

Na teoria freudiana, a denominada "inversão" - tal como o seu suposto contrário -, estaria relacionada com as eleições objetais e com as identificações, necessariamente imbricadas em questões subjetivas - e inconscientes. A sociedade teria imposto a problemática necessidade de uma "cura" para aquela, mas a psicanálise não a considera uma doença e, nesse sentido, oferece, às pessoas que se identificam como homossexuais, o mesmo que oferece às pessoas que se identificam de outro modo em relação à orientação sexual: a investigação de suas orientações amorosas e de sua identidade. Freud se dedica a tal investigação e, assim, Sidonie revela aspectos acerca da constituição de seus laços afetivos que evidenciam, por sua vez, o fato de sua homossexualidade se relacionar com suas questões subjetivas.

A investigação da rede de relações da jovem permitiria a composição de um quadro envolvendo as figuras parentais de Sidonie, bem como seu irmão mais velho. Em decorrência de um deslocamento edípico, ela teria, no irmão, um objeto de atração sexual. Nesse contexto, por objeto de atração sexual, entende-se a representação para a qual ela dirigirá sua libido - ou seja, que comporá um traço identificatório e que será reconhecido como alguém não somente valioso, mas que irá satisfazê-la. Isso, simbolicamente, pois o complexo de Édipo se configura como um jogo de posições subjetivas internas - ou seja, como imagos. E Freud discutiria as mencionadas nuances da subjetivação desde os "Três Ensaios Sobre a Sexualidade Humana" (FREUD, 1976c; SARTORI; MANTOVANI, 2016).

Mas a mãe de Sidonie também se constituiria como objeto de atração sexual, decorrendo daí sua possível definição inconsciente como alguém que buscaria um parceiro amoroso que satisfaria seu duplo objetivo sexual: a atração por figuras tanto femininas como masculinas. Sua amiga mais velha, personagem de sua trama, representava esse ideal do eu: "Assim, sua última escolha correspondia, não só ao ideal feminino, como também ao masculino; combinava a satisfação da tendência homossexual com a da tendência heterossexual. É bem sabido que a análise de homossexuais masculinos em numerosos casos revelou a mesma combinação, o que deveria nos alertar contra formarmos uma concepção demasiado simples da natureza e da gênese da inversão e mantermos em mente a bissexualidade universal dos seres humanos" (FREUD, 1976a, p. 195).

Tal bissexualidade universal dos seres humanos residiria nesse caráter fluido da sexualidade que compreende a inexistência de uma pré-determinação da eleição de objetos (sexuais), que não se relacionaria aprioristicamente com uma suposta essência - como a diferença anatômica. A busca pelo objeto de atração sexual estaria relacionada com aspectos subjetivos em um processo dinâmico.

Por outro lado, uma instituição social como o casamento colocaria em movimento essas categorias identificatórias: "Em todos nós, no decorrer da vida, a libido oscila normalmente entre objetos masculinos e femininos; o solteiro abandona seus amigos homens, ao casar-se, e retorna a vida de clube quando a vida conjugal perdeu o sabor" (FREUD, 1976a, p. 196). Em seu entendimento, um homem casado se voltaria em intimidade para sua mulher.

\footnotetext{
${ }^{17}$ Para Freud (1976a), os impulsos de auto-conservação seriam menos intensos que os impulsos sexuais. Assim, um desejo homossexual não estaria submisso à necessidade de se manter o organismo vivo e adaptado, mas, em seu lugar, seguiria em direção à sua satisfação.
} 
Mas, caso voltasse a ser solteiro, investiria na amizade com homens. Isso não significaria que ele teria relações sexuais com outros homens, mas que sua libido estaria em trânsito e ele investiria na proximidade com seus amigos do sexo masculino. Voltar-se-ia para o domínio dos homens solteiros, entendida como uma 'subcategoria' de homem. Disso, apreende-se o componente social implicado nas relações afetivas e eróticas: um homem casado vive sua afetividade diferentemente de um homem solteiro.

Como se nota, Sidonie buscava um objeto de atração sexual que satisfizesse sua dupla identificação amorosa: “A inversão da jovem, entretanto, recebeu o reforço final quando descobriu em sua 'dama' um objeto que prometia satisfazer não apenas suas inclinações homossexuais, como também aquela parte de sua libido que ainda se achava ligada ao irmão" (FREUD, 1976a, p. 199). Tal consideração freudiana demonstraria, em relação ao psiquismo de Sidonie, suas relações internas - como as imagos.

Ainda, apesar de a chamada "inversão" compreender uma atitude contrária às normas de conduta então vigentes - referentes aos costumes sexuais preconizados para uma mulher -, Freud faz uma consideração que permite entrelaçar a vida de Sidonie ao movimento feminista então nascente, legitimando-o: "Era na realidade uma feminista; achava injusto que as meninas não gozassem da mesma liberdade que os rapazes e rebelava-se contra a sorte das mulheres em geral" (FREUD, 1976a, p. 209). Tem-se, aqui, um ponto de cruzamento entre questões subjetivas (psicológicas) e sociais (culturais). O drama de uma jovem que, contrariando as normas sociais de então, lançava-se a relacionamentos homoafetivos, era, sob um duplo vértice, tanto uma forma de resolução de questões subjetivas, singulares - como sua dupla identificação amorosa, simultaneamente com figuras masculinas e femininas -, como uma forma de militância social, então em desenvolvimento no cenário europeu - o movimento feminista, que reivindicava direitos iguais entre homens e mulheres. Nesta perspectiva, sua atitude teria um caráter revolucionário - ou rebelde, transgressor - ao não se enquadrar na normatização socialmente imposta ${ }^{18}$.
O caso clínico discutido permitiria, ainda, uma exemplificação, fundamentada na psicanálise freudiana, da possibilidade de se reconhecer as categorias identificatórias [relacionadas à sexualidade e ao gênero], bem como o juízo que se faz acerca destas, como construções sociais histórica e socialmente situáveis, que constituiriam fenômenos não pré-determinados diferentemente de elementos constitutivos decorrentes de fatores genéticos e epigenéticos, pré-determinados. Frente à crítica, mesmo os termos 'masculino' e 'feminino', que compõem o par inicial e fundamental das questões referentes à sexuação e à generização, não se permitiriam colocar em termos deterministas.

Também, apesar de a mencionada conceituação dicotomizada - entre 'masculino' e 'feminino' - se fundamentar em uma estereotipia, não se poderão reduzir os seus possíveis termos a meros pares de opostos. Assim, exemplificando-se o exposto, estes não seriam redutíveis à diferenciação entre atitudes ativas e passivas, respectivamente. Freud (1976a) não nega o aspecto "animal" do ser humano, mas, no que se refere às definições subjetivas, incluindo-se, nisso, as definições de gênero, promove a abertura para uma perspectiva não reducionista: "A psicanálise possui uma base comum com a biologia, ao pressupor uma bissexualidade original nos seres humanos (tal como nos animais). Mas, a psicanálise não pode elucidar a natureza intrínseca daquilo que, na fraseologia convencional ou biológica, é denominado de 'masculino' e 'feminino'; ela simplesmente toma os dois conceitos e faz deles a base de seu trabalho. Quando tentamos reduzi-los mais ainda, descobrimos a masculinidade desvanecendo-se em atividade e a feminilidade em passividade, e isso não diz o bastante" (FREUD, 1976a, p. 211).

Por fim, assinala-se que a identificação subjetiva segundo uma categoria identificatória específica - seja referente a sexo, gênero, raça/etnia, orientação sexual, ou outra - resultará de um processo singular que, em última análise, partirá de uma disposição humana universal formalizada e denominada, por Freud, como o

${ }^{18}$ Reitera-se o fato de que o suposto "tratamento" da jovem fora solicitado pelos seus pais. Ela, em si, não embarcou em um pretenso processo de "cura" de suas paixões. Nem Freud (1976a) desse modo a abordou. Ela era homossexual e feminista, o que não implica psicopatologia. 
polimorfismo - denotando, justamente, a não determinação apriorística dos direcionamentos pulsionais.

\section{Considerações Finais}

A proposição de uma releitura dos textos fundamentais da psicanálise como meio de ampliação do debate em torno das questões de gênero, não se limita à reconsideração acerca da importância das ideias freudianas para o tema. Como conhecimento fundamentado na prática da escuta clínica, a teoria psicanalítica se faz indissociável do exercício direto de entendimento do sujeito humano enquanto ser vivente, contextualizado, dialetizado e inscrito em domínios socioculturais.

O caso de Sidonie Csillag não se restringe a ser um estudo acerca da psicoterapia de uma mulher homossexual. Trata-se, antes, de um retrato multifacetado de uma personagem de época - uma mulher que desafiou certas normas de conduta de seu sistema sociocultural, mais especificamente, o padrão socialmente preconizado sobre as práticas amorosas/sexuais. A análise de Freud não somente trouxe à tona o debate acerca da gênese do comportamento sexual humano, mas, ainda, ratifica a noção, atual, de que a(s) homossexualidade(s) não consiste(m) em processo(s) patológico(s) e de que as práticas sexuais são sempre contextualizadas socioculturalmente. A expressão da conduta manifesta a ordem social vigente e os componentes culturais que concorrem nos processos constitutivos da subjetivação. Os modelos de identificação e os ideais do eu (FREUD, 1976b) a serem tomados, inscrevem-se no universo simbólico de cada comunidade em determinado período de tempo. Assim, uma leitura essencialista e reducionista da sexualidade e de gênero esbarraria fatalmente nas exigências não-essencialistas e não-reducionistas dos estudos sobre o tema e na necessidade de se contextualizar aquele que se faria o sujeito a ser investigado.

Atualmente, o comportamento amoroso de Sidonie Csillag talvez não se fizesse tão polêmico como naquele momento e tivesse maior abertura de significação em decorrência das referências atuais sobre a sexualidade. Mas, o que Freud - por meio da psicanálise -, oferece como contribuição para o estudo do tema, é a atitude enfatizada de se privilegiar a escuta do sujeito, não o reduzindo às expectativas sociais, externas ao mesmo. Para a psicanálise, a(s) homossexualidade(s) não se faz(em) processo(s) psicopatológico(s) e, nesse sentido, não poderia haver uma "cura da(s) homossexualidade(s)", mas, sim, a escuta de um sujeito que se assume em categoriais identificatórias, investigando-se as nuances concernentes às suas identificações e às suas eleições objetais. Assim, a psicanálise oferece uma possibilidade de entendimento a respeito do modo como um sujeito se posiciona frente a si mesmo e, consequentemente, frente à sociedade, pois, como a própria Sidonie mostrou-e Freud, então, reconheceu -, consistira, ela, em uma feminista.

\section{Referências}

BUTLER, J. Gender trouble. New York: Routledge, Chapman \& Hall, 1990.

CECCARELLI, P. Mal-estar na identificação. Boletim de Novidades da Livraria Pulsional, São Paulo, v. 93, p. 37-46, 1997.

CECCARELLI, P. Psicanálise, sexo e gênero: algumas reflexões. In: RIAL, C.; PEDRO, J.; ARENDE, S. (Org.). Diversidades: dimensões de gênero e sexualidade. Florianópolis: Mulheres, 2010. p. 269-285.

FREUD, S. A psicogênese de um caso de homossexualismo numa mulher. In: . Além do princípio do prazer, psicologia do grupo e outros trabalhos (1920-1922). Rio de Janeiro: Imago, 1976a. (Edição Standard Brasileira das Obras Psicológicas Completas de Sigmund Freud, v. 18). p. 159-186.

FREUD, S. Psicologia de grupo e a análise do ego. In:___ Além do princípio do prazer, psicologia do grupo e outros trabalhos (1920-1922). Rio de Janeiro: Imago, 1976b. (Edição Standard Brasileira das Obras Psicológicas Completas de Sigmund Freud, v. 18). p. 79-92.

FREUD, S. Três ensaios sobre ateoria da sexualidade. Rio de Janeiro: Imago, 1976c. (Edição Standard Brasileira das Obras Psicológicas Completas de Sigmund Freud, v. 7). 
LAPLANCHE, J. Le genre, le sex, le sexual. In:

CHABERT, C. (Org.) Sur la théorie de la seduction.

Paris: Édition In Press, 2003.

LATTANZIO, F. F. O lugar do gênero na psicanálise: da metapsicologia às novas formas de subjetivação. 2011. 195 f. Dissertação (Mestrado em Psicologia) - Universidade Federal de Minas Gerais, Belo Horizonte, 2011.

RIBEIRO, P. C. Identificação passiva e a teoria da sedução generalizada de Jean Laplanche. Percurso, São Paulo, v. 44, p. 79-90, 2010.

RIEDER, I.; VOIGT, D. Desejos secretos: a história de Sidonie C., a paciente homossexual de Freud. São Paulo: Companhia das Letras, 2008.

SARTORI, J.; MANTOVANI, A. Psicanálise, sexualidade e gênero: a abertura à relativização cultural e o diálogo com a etnopsicanálise. Revista Saúde \& Transformação Social, Florianópolis, v. 7, n. 3, p. 166-175, 2016.

STENNER, A. A identificação e a constituição do sujeito. Psicologia: Ciência e Profissão, Brasília, v. 24, n. 2, p. 54-59, 2004.

STOLLER, R. The mother's contribution to infantile transvestic behavior. Internacional Journal of Psycho-Analysis, Malden, v. 47, p. 384-395, 1966. 